DOI https://doi.org/10.36059/978-966-397-130-8/156-166

\title{
DOCTORAL STUDENTS' RESEARCH SELF-EFFICACY AS A PREDICTOR OF ACADEMIC WRITING CULTURE
}

\author{
Boychuk P. M., Fast O. L., Martyniuk A. P.
}

\section{INTRODUCTION}

The application of Bandura's ${ }^{1}(1977,1997)$ self-efficacy theory to career behavior is arguably one of the most important advances in vocational theory. Self-efficacy, which in general terms represents one's confidence in being able to perform a given behavior, is believed to be a relevant factor in one's career choice and persistence in a career field. Because of the importance of self-efficacy in vocational theory, the assessment of self-efficacy represents an increasingly important part of career assessment.

Between 1994 and 1998 alone three instruments designed to measure graduate students' research self-efficacy have been reported. Although the definition of research self-efficacy is generally consistent across each instrument, different groups of research tasks are represented on these three instruments. As such, it is hard to understand exactly why and how research self-efficacy may be relevant to career outcomes because items on these instruments are drawn from different content domains. Also, it may be hard for mentors and career guidance professionals to provide effective interventions because of uncertainty about which specific tasks students consider when evaluating their own research self-efficacy. This problem could be addressed by determining the dimensions of research self-efficacy assessed by each instrument as well as those dimensions that exist across all three instruments. Indeed, addressing these issues was the purpose of this research.

La Pidus (1998) describes the doctoral educational process as preparing students for scholarship through various roles and responsibilities. Within the framework of doctoral education, other scholars have stated that research is central to doctoral study and the student's ability to create, expand, question, test, integrate, organize, and

\footnotetext{
${ }^{1}$ Bandura, A. (1977). Self-efficacy: Toward a unifying theory of behavioral change. Psychological Review, 84(2).
} 
communicate knowledge is considered essential to a successful educational process (LaPidus, 1995,1998). Thus research, regardless of the academic writing culture is a very important aspect of doctoral training.

\section{Research Self-Efficacy Concept}

The concept of self-efficacy is underscored by a person's belief in his or her ability to perform a certain task. Bandura (1977) posited that selfefficacy encompasses more than the ability to execute a task, rather it involves the person's "thought processes, motivation, affective and psychological states"2. According to Bandura, self-efficacy may be enhanced by the persistence in subjectively difficult activities through experiences of mastery. According to the literature on self-efficacy research, self-efficacy has played an important role in predicting graduate student interest in conducting research (Bishop \& Bieschke, 1998).

There are several studies that examine the construct of research selfefficacy. Phillips and Russell (1994) investigated the relationship between research self-efficacy (RSE), perceptions of the RTE, and productivity for counseling psychology doctoral students. The findings indicated that there was a positive correlation between RSE, RTE and research productivity. Contrary to the predicted hypothesis, a significant correlation was not found between RSE and research productivity and the participants. The population of the study was comprised of a national sample of 219 doctoral students and interns in counseling psychology. The respondents completed a demographic questionnaire, the SERM (Phillips \& Russell). A potential limitation was that this study was correlational in nature and thus did not lend itself to making inferences about the casual relationships between the variables. A strength of the study was that the instruments used demonstrated good internal consistency with the SERM having a chronbach's alpha of .96 and the RTES of .92, respectively. The study provided insight into the relationships between RSE, RTE, and research productivity as they related to counseling psychology doctoral students and interns.

Forrester, Kahn and Hesson-McInnis (2004) investigated research self-efficacy and addressed the factor structures of three measures of research self-efficacy using the following:

(a) The Research Self-Efficacy Scale (RSES; Greeley et al, 1989),

\footnotetext{
${ }^{2}$ Bandura, A. (1977). Self-efficacy: Toward a unifying theory of behavioral change. Psychological Review, 84(2), p. 36.
} 
(b) SERM (Phillips \& Russell, 1994) and

(c) Research Attitudes Measure (RAM; O'Brien, Malone, Schmidt, \& Lucas, 1998).

The study measured confidence through a number of tasks related to the selection of methodology, data collection, entry, analysis, interpretation, and writing. According to Forrester and colleagues, O'Brien et al's six dimensions of research self-efficacy were "discipline and intrinsic motivation, analytical skills, preliminary conceptualization skills, writing skills, application of ethics and procedures, and contribution and utilization of resources"3.

Forrester and colleagues (2004) conducted the study to test the hypothesized factor structures empirically. The study was comprised of 1,004 graduate students in counseling psychology programs nationwide. Each participant completed three measures of self-efficacy via an online survey method. The primary hypothesis was that measures of RSE had the ability to be facilitative in the training and mentoring of graduate students. However, confirmatory factor analysis did not support the factor structures that were hypothesized. The primary limitation was that the study was only generalizable to students studying counseling psychology despite the relatively large sample size.

Mullikin, Bakken, and Betz (2007) investigated research self-efficacy with respect to physician scientists and examined the effects of human agency on the career development of physician researchers. The researchers initially created a 92-item Clinical Research Appraisal Inventory (CRAI; Mulliken, Baken \& Betz, 2007), which they later modified to address 88 items. The researchers surveyed a national sample of 210 physicians within academic medicine and found that the CRAI reliably measured eight dimensions of research self-efficacy.

Limitations of the study included a small sample size and an inability to attract diversity within the sample population. This was the first study to address research self-efficacy in the clinical research domain using a population of academic physicians and thus provides significant insight into the relationship between research self-efficacy and career development with regard to physician scientists.

\footnotetext{
${ }^{3}$ O’Brien, K. M., Malone, M. E., Schmidt, C. K., \& Lucas, M. S. (1998). Research self-efficacy: Improvements in instrumentation. Poster session presented at the annual conference of the American Psychological Association, San Francisco. p. 5.
} 
Unrau and Beck (2004) explored the relationship between research self-efficacy and course enrollment in graduate programs. The sample included 60 social work and 75 speech language pathology students. In order to determine how course enrollment affected research self-efficacy, the study evaluated gains in research self-efficacy between students enrolled in both research and practice courses as well as those only enrolled in practice courses. The motivation behind the survey was to understand the perceived lack of emphasis on research training with social work and speech-language pathology students. The study used RSE scores to evaluate self-efficacy gains. The results indicated that students the majority of students experienced gains in confidence. Students enrolled in both the research and practice classes showed the most significant gains and when research was aligned with learning opportunities outside of the classroom, self-efficacy gains were the greatest. The speech language pathology students improved roughly 30 points on the total RSE score over 16 weeks, compared with the next largest increase of roughly 18 points. Limitations of the study included several known threats to internal validity, namely history, maturation, regression, and differential selection effects. Nevertheless, the study contributed to the limited literature regarding the relationship between research self-efficacy and class enrollment.

Geisler's (1995) study examined the relationship between research self-efficacy and counseling psychology students' dissertation progress. The instrumentation included: (a) Scientist-Practitioner Inventory for Psychology (SPI), (b) Research Training Environment Scale (RTES), (c) Self-Efficacy Measure (SERM), and (d) Demographic and Research Questionnaire.

The sample comprised of 331 counseling psychology doctoral students randomly selected from 24 APA approved programs. Findings suggested that research self-efficacy was positively correlated to dissertation progress with perceptions of the research-training environment not a significant factor. Additional results indicated that scientific interest and research self-efficacy were positively related, and that research selfefficacy was the most influential predictor of dissertation progress.

There were several limitations inherent in the study. There was no way to determine the differences between perceptions of students who had responded and those who had not. The study measured the students' perception of their environment, not the environment itself, and did not 
take into account faculty perceptions of the training environment. Because the study was based on self-reporting, there was potential for biased responses. The overall response rate was 30\%, which is below average (Dillman, 2007). Additionally, the study was limited to APA approved counseling psychology doctoral students and therefore generalizability of results may not be possible. In summary, the study contributed to the counseling psychology literature as it provided insight into the relationship between self-efficacy and doctoral students' dissertation progress.

Faghihi (1998) examined the effects of mentoring on dissertation progress of 97 doctoral students at the University of Memphis, representing the disciplines of counseling, educational psychology, research and curriculum instruction, and leadership. Instrumentation included a researcher-developed 61-item dissertation questionnaire. The results suggested that the role of faculty advisors and committee members was significant in the students' progress toward dissertation completion. Students who indicated that they had positive and cooperative relationships with advisors and committee members were more advanced in the writing of their dissertation than others. Faghihi concluded that research efficacy was a function of a positive and nurturing research environment as well as a strong supervisory system.

There were some limitations to Faghihi's (1998) study. The sample consisted of doctoral candidates at the College of Education at The University of Memphis, which limited the generalizability. The independent variables could not be manipulated and therefore causation could not be inferred. Using a self-report questionnaire could have resulted in response bias. In addition, the instrument utilized did not have a demonstrated track record of reliability and validity in the literature. The study contributed to the literature because it examined students' dissertation progress in relation to RTE, involvement in research, research training/preparation, graduate assistantships, student-advisor relationships, and research self-efficacy.

Tang and colleagues (2004) examined the relationship between counselor education graduate students' self-efficacy with regard to counseling skills. One hundred and sixteen participants were recruited from six counselor education programs located in the Midwestern region of the United States. Three of the six programs were CACREP-accredited. To gather demographic information, a researcher-developed questionnaire was 
created that included items such as: age, gender, race, years of human services work experience, hours of clinical instruction, number of clinical courses taken, and student enrollment status (part- or full-time).

Tang et al. (2004) found that the total scores of self-efficacy between graduate students from CACREP and non-CACREP-accredited programs did not differ. The lack of differences between the two groups occurred when controlling for amount of course work, hours of internship, and prior work experience. There were differences found between the two groups in that students from CACREP-accredited programs had higher levels of selfefficacy in counseling anxiety reactions, assessment using clinical interviews, counseling adjustment reactions, and counseling affective disorders. Limitations of the study included the regional geographic sample and the fact that information about training and internship hours was selfreported. The findings are a significant contribution to counselor education literature as results suggested that the main source of variation in student self-evaluation with regard to counseling skills was the number of training hours and the amount of previous relevant work experience they had. This study supports Bandura's (1986) theory of self-efficacy, which asserts that past experiences and real world involvement in related tasks assist students in developing more confidence in accomplishing tasks.

\section{Academic Writing Competencies}

Even though many scholars have suggested ways of improving research training in doctoral education, there has been a growing concern about the research

competencies of counselor educators (Kline \& Farrell, 2005; Reisetter et al., 2004). For instance, Fong (1992) wrote an editorial article entitled "When a Survey Isn't Research" in Counselor Education and Supervision, a prominent journal for the counselor education profession. Fong noted as editor of the journal in 1992 that she often received large numbers of survey studies with poor research designs which made them unpublishable (Fong, 1992). In another article, Fong and Malone (1994) examined 111 manuscripts submitted for publication in Counselor Education and Supervision. They reviewed these articles to determine the types of errors presented in the article submissions and concluded from their findings that some doctoral students had serious problems with poorly designed and executed research. For example, they discovered that out of the 55 
manuscripts classified as research studies 32 had research design errors which made the findings invalid.

Although the two articles Fong wrote were published over 15 years ago, current scholars have also noted research competencies concerns among doctoral students.

Kline and Farrell (2005) wrote an editorial in Counselor Education and Supervision also highlighting the frequent and recurring research related errors found in manuscripts submitted for publication during that year. Kline and Farrell noted that of the 227 manuscripts submitted for publication to the journal $47 \%$ were rejected because of the following reasons: (a) problems with the format required for submitting articles, (b) errors in qualitative and quantitative research methods, and (c) low response rates with survey studies. Typically, when scholars like Fong (1992), Fong and Malone (1994), and Kline and Farrell have discussed these research deficiencies in counselor educators, they have pointed to doctoral research training as the source of their challenges with research skills. However, many scholars have suggested doctoral training is the place where graduate students should not only become interested in research but also it is the time upon when they learn how to perform research related activities (LaPidus, 1995).

Academics are expected to publish in strong, nationally refereed journals (Glatthorn, 2002). McGrail, Rickard and Jones (2006) noted that promotions in academia were often based on a successful record of scholarly publications. Traditional motivation to publish articles, such as scientific inquiry and the importance of disseminating knowledge in nationally refereed journals remains important. Yet, in the current university climate "publication rates are used as both an indicator of individual and institutional performance and are important criteria in achieving external funding from government and other professional bodies" (McGrail et al. \& Jones, 2006, p. 19). Therefore, having students and/or faculty members publish articles in nationally refereed journals not only improves the standings of the individual researcher, but also improves the credibility and image of the university as well.

Love, Bahner, Jones, and Nilsson (2007) supported the idea that students who published scholarly works during their time as doctoral students had an advantage of being looked upon favorably in the hiring process. Love and colleagues found that students who had access to 
effective research mentorship were more likely to become involved in research activities than those who were not exposed to such mentoring.

Many researchers have offered suggestions for addressing the issue of preparing doctoral students to become researchers (Eisenhart and Dehaan, 2005). Eisenhart and Dehaan (2005) advocated an approach that immerses students into a "culture of science" (p. 3) and encourages them to pursue scientific inquiry. They point to the following areas where programs might consider concentrating their research training efforts: (a) core research courses, (b) research experience, (c) teaching experience, and (d) interdisciplinary collaborations.

\section{CONCLUSIONS}

The doctoral education literature has shown a paucity of research using the constructs of research activity and academic writing competencies. Additionally, the literature indicates that the research training of doctoral students is an area of concern. Therefore, research that investigates constructs relating to the research development of doctoral students is both necessary and timely.

Despite the emphasis on training doctoral students to become both scientists and practitioners, research supports the premise that doctoral students demonstrate low levels of research productivity. In an effort to increase research involvement in the counseling field, many researchers have looked at the issue of training in research through both empirical and conceptual lenses.

In summary, a student's preparation and environment may have a significant impact on their research self-efficacy, research experience, teaching experience and interdisciplinary collaborations.

\section{SUMMARY}

Based on the analysis of foreign sources on the problem of forming the research self-efficacy of doctoral candidates, it was found that this phenomenon is multifaceted and quite debatable. The experience of leading world-class universities shows that the process of improving scientific leadership, mentoring as educational institutions is important in the formation of doctoral candidates' research self-efficacy. This has stimulated foreign scholars to seek new, alternative models for organizing 
postgraduate research leadership, including group supervision, as well as the potential of cohort-based pedagogies.

Even though many scholars have suggested ways of improving research training in doctoral education, there has been a growing concern about the research competencies. Despite the emphasis on training doctoral students to become both scientists and practitioners, research supports the premise that doctoral students demonstrate low levels of research productivity. In summary, a student's preparation and environment may have a significant impact on their research self-efficacy, research experience, teaching experience and interdisciplinary collaborations.

\section{REFERENCES}

1. Bandura, A. (1977). Self-efficacy: Toward a unifying theory of behavioral change. Psychological Review, 84(2), 191-215.

2. Bishop, R. M., \& Bieschke, K. J. (1998). Applying social cognitive theory to interest in research among counseling psychology doctoral students: A path analysis. Journal of Counseling Psychology, 45,182-188.

3. Dillman, D. A. (2007). Mail and Internet surveys: The tailored design method. New York, NY: John Wiley and Sons.

4. Eisenhart, M., \& DeHaan, R. L. (2005). Doctoral preparation of scientifically based education researchers. Educational Researcher, 39(4), $3-13$.

5. Faghihi, F.Y. (1998). A study of factors related to dissertation progress among doctoral candidates: Focus on student research selfefficacy as a result of their research training and experience. Dissertation Abstracts International, 59(05), 1456A. (UMI No. AAG9834228).

6. Fong, M. L., \& Malone, C. M. (1994). Defeating ourselves: Common errors in Counseling research. Counselor Education and Supervision, 33, 356-362.

7. Forester, M., Kahn, J. H., \& Hesson-McInnis, M. (2004). Factor structures of three measures of research self-efficacy. Journal of Career Assessment, 12, 3-16.

8. Geisler, C. C. (1995). Scientist-practitioner interests, research selfefficacy, perceptions of the research training environment and their relationship to dissertation progress. Dissertation Abstracts International, DAI-A 57/02 (UMI No. 9619812). 
9. Glatthorn, A. (2002). Publish or perish--the educator's imperative: Strategies for writing effectively for your profession and your school. Corwin Press: California.

10. Greeley, A. T., Johnson, E., Seem, S., Braver, M., Dias, L., Evans, K., Kincade, E., \& Pricken, P. (1989). Research Self-Efficacy Scale: Unpublished scale. The Pennsylvania State University.

11. Kline, W., \& Farrell, C. (2005). Recurring manuscript problems: Recommendations for writing, training, and research. Counselor Education and Supervision, 44, 166174.

12. LaPidus, J. B. (1995). Doctoral education and student career needs. New Directions for Student Services, 72, 33-41.

13. LaPidus, J. B. (1998). If we want things to stay as they are, things will have to change. New Direction for Higher Education, 101, 95-102.

14. Love, K. Bahner, A. Jones, L. \& Nilsson, J. (2007). An investigation of early research experience and research self-efficacy. Professional Psychology: Research and Practice, 38(3), 314-320.

15. McGrail, M., Rickard, C. \& Jones, R. (2006). Publish or perish: a systematic review of interventions to increase academic publication rates. Higher Education Research and Development, 25(1), 19-25.

16. Mulliken, E., Bakken, L. \& Betz, N. (2007). Assessing research self-efficacy in physician scientists: The clinical research appraisal inventory. Journal of Career Assessment, 15(3), 367-387.

17. O’Brien, K. M., Malone, M. E., Schmidt, C. K., \& Lucas, M. S. (1998). Research self-efficacy: Improvements in instrumentation. Poster session presented at the annual conference of the American Psychological Association, San Francisco.

18. Phillips, J. C, \& Russell, R. K. (1994). Research self-efficacy, the research training environment, and research productivity among graduate students in counseling psychology. The Counseling Psychologist, $22,628-641$.

19. Tang, M., Addison, K. D., LaSure-Bryant, D., Norman, R., O'Connell, W., \& Stewart-Sicking, J. A. (2004). Factors that influence selfefficacy of counseling students: An exploratory study. Counselor Education and Supervision. 44(1), 70-80. 
20. Unrau, Y. \& Beck A. (2004). Increasing research self-efficacy among students in professional academic programs. Innovative Higher Education, 28(3), 187-194.

\section{Information about the authors: \\ Boychuk P. M.}

Candidate of Pedagogical Sciences,

Associate Professor, Rector,

Municipal Higher Educational Institution

"Lutsk Pedagogical College" of the Volyn Regional Council

36 Voli ave., Lutsk, Volyn region, 43010, Ukraine

Fast O. L.

Candidate of Pedagogical Sciences, Associate Professor, Vise-rector on Research, Teaching and International Relations, Municipal Higher Educational Institution "Lutsk Pedagogical College" of the Volyn Regional Council 36 Voli ave., Lutsk, Volyn region, 43010, Ukraine

Martyniuk A. P.

Candidate of Pedagogical Sciences, Associate Professor, Head of the Department of Ukrainian and Foreign Philology, Lutsk National Technical University 75 Lvivska str., Lutsk, Volyn region, 43000, Ukraine 